\title{
Circe y otras alusiones mitológicas en el relato y filme de Cortázar
}

\section{Circe and other mythological allusions in the story and film of Cortázar}

\section{Resumen}

La prolija obra de Julio Cortázar incluyó también el poco conocido ejercicio dramático que conforma un repertorio de varias obras de su autoría, así como algunos cuentos de mejor difusión, y cuyo eje temático se alimenta de los mitos griegos o mesoamericanos, algunos de los cuales se han convertido en guiones cinematográficos. El propósito de este trabajo es marcar una línea de referencia en tono al cuento suyo "Circe" de su libro Bestiario, y en el que el autor colaboró como guionista.

Palabras claves Literatura y cine. Julio Cortázar. Literatura latinoamericana. Mitología clásica. Adaptación cinematográfica.

\begin{abstract}
The neat work of Julio Cortázar also included little known exercise dramatic theirs which constitutes a repertoire of several plays of his own, as well as some stories of best broadcasting, and whose thematic axis is fed myths Greek or Mesoamerican, some of which turned into screenplays. The purpose of this work is to mark a reference line in tone to the story his "Circe" from his book Bestiario, and in which the author worked as screenwriter.
\end{abstract}

Keywords Literature and cinema. Julio Cortázar. Latin American literature. Classical mythology. Film adaptation. 


\section{Generalidades.}

La mitología clásica ha sido desde siempre inspiradora de escritores que retoman algunos pasajes o líneas anecdóticas completas para presentar novedosos productos literarios intentando respetar el modelo tradicional o proponiendo sus personales, diversas y atractivas reinterpretaciones. En fechas tan recientes en el tiempo, por proponer una muestra, la literatura clásica del universo griego (Sófocles, Eurípides, etcétera) ha sido reformulada mediante la óptica de las injusticias cercanas y resentidas de la corrupción, la violencia, la inmigración forzada, etcétera, que ha producido para el teatro "nuevas" Antígonas, Fedras, Edipos y Medeas, como lo muestran las carteleras escénicas latinoamericanas y europeas.

En la literatura escrita en español, un autor emblemático como Julio Cortázar tampoco desdeñó la posibilidad de re-crear aspectos de la mitología mesoamericana en conocidos cuentos de su autoría como "La noche boca arriba" y "Axolotl" de su libro Final de juego, por ejemplo, y de la Grecia clásica que consideró para la escritura de algunos de sus textos. De esta última van a aparecer en este mismo volumen "Las Ménades" y El ídolo de las Cícladas". Por otra parte, haciendo uso de las herramientas que propone la forma dramática, escribiría algunas piezas para la escena, entre ellas Los reyes de 1947 que aborda el mito de Ariadna y el Minotauro.

El propósito de este ensayo es analizar algunas de las estrategias usadas en el relato "Circe" y su traslación al lenguaje cinematográfico, enunciando los efectos de sentido y las negociaciones que se llevan a cabo en este proceso. El objetivo final es proponer un marco de referencia donde incluir la película del mismo nombre, dirigida por Manuel Antín y cuyo guion fue co-escrito por el mismo Cortázar, para mencionar la recepción de la película en el tiempo de su estreno.

Para el estudio textual, lírico y fílmico, considero como marco teórico a tres autores. En primer lugar al filólogo mexicano Ernesto de la Peña quien se ha 
acercado con erudición a los estudios acerca de la cultura proponiendo novedosos como apasionantes enfoques. Para el contenido cinematográfico es fundamental el nombre de Robert Stam que en la Teoría y práctica de la adaptación propone un modelo de abordaje acerca de los aspectos narrativos, temáticos y estilísticos de las adaptaciones de la literatura al lenguaje cinematográfico. Por último retomaré las reflexiones de Antonin Artaud acerca de la participación del espectador en su denominado "teatro de la crueldad", en clara conexión con el cine, con el que siempre mantuvo un carácter ambiguo y complejo.

Como indica Patrice Pavis, bajo esta denominación de "teatro de la crueldad" el autor francés se refiere a una suerte de:

proyecto de representación que somete al espectador a un tratamiento emocional de choque a fin de liberarlo del imperio del pensamiento discursivo y lógico para encontrar una nueva vivencia inmediata. (Pavis 446)

Como una ruta hipotética de trabajo he tenido en consideración el hecho de que no necesariamente las habilidades del autor-narrador corresponden a los aciertos del autor-guionista cinematográfico ya que si bien son actividades intelectuales que se trazan de manera paralela, requieren de evidentes estrategias distintas que no aseguran por sí mismas el favor de la crítica especializada. Así fue la manera en que sucedió con los realizadores de "Circe" cuyo trabajo recibió aciagos comentarios como se da cuenta al final de este artículo.

En este sentido la diferencia entre las habilidades que los autores deben utilizar para la escritura de sus propios textos de naturaleza diversa, puede ser la causa de que los trabajos dramáticos y poéticos de Julio Cortázar no tuvieran la misma aceptación que sus narraciones. La poca o dificultada recepción de sus textos poéticos y dramáticos va a comentarse con el humor característico de este autor, explicitándolo en un tono de intimidad con los lectores: 
Todos los críticos del mundo, prácticamente todos, me han clasificado como prosista, como un cuentista o un novelista. Entonces, cada vez que se ha publicado un poema mío, o bien no ha habido ningún comentario, como si se tratara de una travesura de Julio Cortázar que publicó un poema que no merece ser criticado o comentado, o bien han sido recibidos yo diría casi con una cierta desolación, una cierta tristeza, como quien dice: "Caramba, este hombre que tan bien estaba encausado en su línea de trabajo y ahora se pone a hacer versos". (Cortázar en Prego 212)

En esta nota se advierte el acento lúdico que intenta explicar la falta de atención hacia su obra poética, supeditándola a la abundante crítica enfocada al estudio de su obra en prosa. Es precisamente esta falta de atención hacia los géneros no narrativos de este autor, la que justifica la realización de un trabajo ensayístico como este.

\section{De Los reyes a "Circe".}

En el corpus literario de Cortázar que se deriva de la mitología griega no es tan solo de interés el cuento arriba anunciado, sino también Los reyes la pieza de teatro que inaugura la faceta dramatúrgica de este autor y que fue publicada en 1949. Esta creación da cuenta de una obra de inspiración helenista estructurada en cuatro escenas dialogadas y un monólogo, misma que el autor clasifica adecuadamente como "poema dramático". Un lenguaje casi hierático constituye esta pieza que revive el mito cretense con una óptica distinta a la clásica, opuesta a la tradicional, en donde:

el Minotauro no es allí un monstruo. Lo monstruoso está en Teseo, el héroe, el perseguidor de la gloria y sus prebendas, y en Minos, rey 
cauteloso y despiadado. Para ambos el Minotauro es lo incomprensible y, por tanto, el peligro. (Filer 32)

En Los reyes de hecho el cautiverio de la bestia y la inmolación de las doncellas ofrecidas en sacrificio son acciones impuestas y motivadas por el propio monarca que de esta manera pretende sembrar el miedo para mantener su dominio sobre el pueblo que gobierna y también el de los pueblos vecinos. Y si bien los atenienses se declinan sin cortapisa a proporcionar el tributo que cumplen con puntualidad cada año, también el temor que se extiende hasta otros pueblos de África provoca el prestigio del temible guardián recluido en su laberinto.

Steven Boldy encuentra alusión a la figura del militar y ex presidente argentino Juan Domingo Perón (1985-1974) atrás del propio rey Minos que como Teseo en la pieza de Cortázar, representan el poder despótico. Por su parte, lo «monstruoso» del animal mítico lo va a ser en tanto posee la fuerza desestabilizadora del sistema, razón por la que se le pretende aniquilar: "para que sus palabras [libertarias y subversivas al régimen totalitario] no lleguen a los oídos del pueblo y hagan caer las murallas que los encierran en sus redes de leyes y de tradiciones petrificantes" (Cortázar 53).

El sentimiento de la libertad creadora, señala el propio autor, es el núcleo, la esencia del drama que con notoria evidencia da una vuelta al mundo autocrático de Minos ante la latente amenaza que va a representar para su reinado ese hijo de la bestia concebido con la bella Pasifae.

La repentina brillantez de Cortázar ante la urgente escritura de este drama, va a sucederle como una iluminación durante un trayecto común de autobús de regreso a casa, donde expresa el cuentista devenido aquí en dramaturgo:

Escena tras escena, escribí en unas horas esos diálogos que eran la única manera que me era dada de mostrar otra visión del mito a través de las palabras de los protagonistas. (Cortázar en Bernárdez 248) 
He querido mencionar esta pieza dramática para marcar el interés prematuro de este autor contagiado por el abordaje de temáticas del mundo antiguo. Pocos años después a la escritura de la obra teatral, Cortázar va a recuperar a aquella: "Circe, la de hermosos cabellos, potente deidad de habla humana" (Homero 155) como se le describe en la Odisea y cuya imagen representa una fantasía erótica irresistible. Ella, como allí se anuncia:

Es hermana de Eetes, el dios de la mente perversa; una y otro nacieron del Sol que da luz a los hombres y su madre fue Persa, engendrada a su vez del Oceano. (Homero 155)

Taumaturga y hechicera, la personaje va a tener un tratamiento muy atractivo, moderno y novedoso mediante la breve narración de nuestro autor belga-argentino. De manera casi inmediata vendrá la adaptación como guion cinematográfico de su propia coautoría que filmó su amigo Manuel Antín. Para este joven cineasta la empresa significó el comienzo de su propia vida profesional en el campo de la cinematografía argentina.

La Circe homérica se presenta como una quimera sensual para los náufragos, los recluidos o los hambrientos de placer sexual; será la prenda deseada pero paradójicamente inalcanzable. Según este pasaje, la seductora hechicera convierte en cerdos y otros animales a los hombres como un castigo por la intromisión en la isla Eea que habita. Según señala Ernesto de la Peña, con la práctica de este embrujo ella se libra de cualquier intento de violación por parte de los indeseables intrusos.

En la descripción de Homero leemos que los sedientos y llorosos náufragos de las tropas de Odiseo encontraron las moradas de Circe:

Fabricadas con piedras pulidas en sitio abrigado;

[en donde] allá afuera veíanse leones y lobos monteses hechizados por ella con mal bebedizo [quienes]: se alzaron 
al llegar mis amigos y en vez de atacarlos vinieron a halagarlos en torno moviendo sus colas. (Homero 157)

Señala Ernesto de la Peña que estos marineros recién llegados de altamar: "largamente hambrientos de alimento y de sexo, han de haber querido poseerla una vez que [habrían] saciado su hambre"; luego entonces la maga, al transformarlos en bestias indeseables "demostró su potencia y rompió por lo sano cualquier intento de violación" (De la Peña 477). La hechicera se libra del abuso sexual a la vez que con su acto castiga a los indeseables visitantes.

Colocado como un epígrafe, el cuento "Circe" de Cortázar incluido en el libro Bestiario de 1951, abre con una elocuente cita del pintor, poeta y traductor inglés Dante Gabriel Rossetti (1828 - 1882) fundador de la llamada "Hermandad Prerrafaelista" quien también fue atraído por los temas dramáticos y sobrenaturales. Esta nota demarca el embrujo o seducción de la belleza femenina destinada a la fatalidad:

And one kiss I had of her mouth, as I took the apple from her hand. But while I bit it, my brain whirled and my foot stumbled; and I felt my crashing fall through the tangled boughs beneath her feet, and saw the dead white faces that welcomed me in the pit. ${ }^{1}$ (Rosetti en Cortázar 144)

En el relato de Cortázar se van a describir las habladurías que suceden en el barrio de Almagro, en torno a Delia Mañara: "la muchacha [de apenas veintidós años] que había matado a sus dos novios" (Cortázar 144). Desde pequeña la joven bonaerense demostró encanto y seducción para los animales de casa: los gatos, perros, mariposas y hasta las arañas se doblegan arrobados.

1 "Y un beso obtuve de su boca, cuando tomé la manzana de la mano. Pero mientras la mordía, mi cabeza dio vueltas y mi pie tambaleó; y sentí caer estrepitosamente a través de las ramas enmarañadas debajo de sus pies, y vi los blancos rostros muertos que me dieron la bienvenida en el pozo", The Orchard-Pit. 
Tan bella como misteriosa, ella es descrita en el vecindario bajo la sospecha de ser practicante de la magia negra porque además, como complemento a este seductor alto calado suyo, la muerte le sigue los pasos ya que sus dos anteriores novios fallecieron de manera sorpresiva e incierta. De sus prometidos, primero fue Rolo Médicis que sufrió un síncope cardíaco provocándole una aparatosa caída con fractura de cráneo, en el mismo zaguán de los Mañara; luego murió Héctor quien inexplicablemente se suicidó pocas horas después de haber salido de la casa de Delia.

La joven tiene un poder que igual hipnotiza a los animales domésticos como a otros muchachos de su edad que la rodean. Ella complementa su grácil devaneo con la dádiva demostrada en la preparación exquisita de licores, postres y pequeñas confituras como galletas o bombones; experimenta con las combinaciones delicadas de sus ocultas recetas que hace degustar ahora a Mario como hizo antes con los ya difuntos Rolo y Héctor. Mario, este nuevo acompañante, le demuestra honesta devoción; pasado un corto tiempo, se le propone en matrimonio aún a pesar de las habladurías vecinales y de los fehacientes textos anónimos que recibe con mensajes que le advierten del peligro: "Yo que usted tendría cuidado con el escalón de la cancel" (Cortázar 152) cuyo escrito hace alusión al accidente del tristemente desaparecido Rolo.

La relación entre estos dos jóvenes, luego que se ha hecho la propuesta matrimonial y con ésta el tránsito de supuesta amistad a un firme compromiso nupcial, ahora va a cambiar de raíz como bien se lo hace saber la hermosa Delia a su prometido: “- Entonces sos mi novio -dijo-. Qué distinto me parecés, qué cambiado" (Cortázar 151). Se entiende de ello que el establecimiento de una relación formal pone en peligro el bienestar físico del pretendiente cuando éste se convierte también en su degustador habitual. Él suministra los ingredientes primordiales a la chica para la elaboración de sus platillos, además de que prueba y aprueba las galletitas preparadas con hojas amargas, las masas crocantes, los levísimos sabores a mandarina, los sutiles licores resultantes de una secreta como minuciosa alquimia inventada. 
Vale distinguir por otra parte, el voseo de la chica que aparece como contrapunto a la historia mitológica oficial. Al mismo tiempo esta modalidad va a otorgar sencillez, cercanía y cotidianidad al hecho que narra el cuento.

$\mathrm{Si}$ en el poema homérico Circe vierte su pócima encantada en los alimentos de los intrusos que a su ingesta los convierte en leones, cerdos o lobos monteses, en el texto de Cortázar, Delia va a ofrecerle a su tercer novio otra porción de su deleitosa confitería; pero Mario advertido por los gemidos y la excitación de su prometida ante la peligrosa ingesta que está a punto de tragar, aprieta los flancos del bombón para descubrir en su interior el revestimiento fibroso de una cucaracha y a su alrededor los trocitos de patas y alas que van a hacerse visibles ya con el minúsculo caparazón triturado.

Mario, como le sucedió antes a Odiseo, se libra del embrujo: el segundo a merced de la milagrosa moly o 'molu', la planta que recibió del divino Hermes cuyas benéficas flores "vencen la influencia nociva y los malos efectos de cualquier otra hierba" (De la Peña 478). La protección que el personaje homérico recibe se advierte en el siguiente pasaje:

el divino Argifonte entregóme una hierba que del suelo arrancó y, a la vez, me enseño a distinguirla; su raíz era negra, su flor del color de la leche; 'molu' suelen llamarla los dioses; su arranque es penoso para un hombre mortal; para un dios todo, en cambio, es sencillo. (Homero 160)

Por su parte el inteligente joven bonaerense del cuento se protegerá del hechizo deduciendo el elocuente nerviosismo y la ansiedad de la muchacha al momento en que ella le ofrece el infausto bocadillo. Debido a la capacidad de observación y suspicacia, la intención de producir el mal va a ofuscarse.

Como antes se hizo referencia, se tiene disponible la versión cinematográfica del cuento "Circe" que fue dirigida por Manuel Antín y estrenada 
el 30 de abril de 1964. El texto de la adaptación fue realizado a tres manos en donde participaron el propio Cortázar, el guionista Héctor Grossi y el director del filme.

De entrada durante los primeros minutos del filme, en los tres jóvenes varones que son amigos entre sí, se concentran las habladurías del barrio que resaltan los atributos físicos de la joven Delia, y de la fuerza de atracción derivada de su lozanía; pero sobre todo sus comentarios van a girar en torno a las extrañas muertes de los dos novios suyos anteriores. Durante estas conversaciones expresadas con un tono de camaradería sincera, los chicos le advierten a Mario de esta peculiaridad nada común.

La cámara enfoca el rostro de Delia. El semblante afligido que transmite una pena infinita va a resaltarse con el buen contrapunto expresivo del blanco y negro de la película. Este claro oscuro subraya también la vestimenta de "la viudita" como la llegan a mencionar los de su barrio, pues ella todavía viste una suerte de luto perenne en memoria del difunto Héctor.

La proyección intercala enseguida los episodios que muestran el asecho y la constante persecución de Mario cuando ella sale de la iglesia o en el malecón donde la intercepta para declararle su deseo que finalmente Delia va a consentir. Él se convierte desde entonces en su íntimo confidente a quien le habla del pasado, de su soledad y el martirio culposo por una acción que no revela.

Ella le habla con una naturalidad hiriente acerca de sus novios anteriores, cuenta las atenciones de su Rolo, quien siempre -dice- la llenó de regalos, y de Héctor a quien todavía le guarda duelo; pero en contrapartida se muestra renuente a los cariños físicos que le ofrece Mario al que le rehúye los besos, construyendo con su distancia emotiva una chocante barrera invisible mediante la práctica de los constantes juegos de tensión y distensión entre ambos.

A merced del trabajo de montaje del filme que tiene una duración de apenas una hora $\left(59^{\prime} 53^{\prime \prime}\right)$, se aprecian escenas intercaladas que van a reiterar la muerte de los prometidos anteriores mediante la incorporación de breves analepsis. En este montaje la cámara va a recuperar la escena de Rolo cuando 
sufre un ataque al corazón y cae a los pies de Delia quien inmutable solo lo observa sin proporcionarle auxilio, y la de Héctor que sin explicación cierta se arroja al río desde un puente.

Se entrevera también en la narrativa visual la obsesión de ella ante los espejos de su casa, proponiendo en principio lentos roles de contemplación, luego de autoseducción y de prácticas eróticas que realiza en solitario. El tratamiento sicologista marcado por el acercamiento de la cámara que no pierde el detalle de las reacciones de la protagonista y de los demás personajes, va a permitir una forma viva y atractiva que apoya la definición del carácter otorgando suspenso al avance de la historia.

En la película los padres de Mario que no ocupan lugar relevante en el texto de origen, preocupados por la tan distinta conducta taciturna de su hijo antes festivo y rebosante de afecto, acuden a visitar a los respectivos progenitores de Delia en la búsqueda de respuestas ante el abrupto cambio de su carácter; pero ya en la privacidad del encuentro, todos sostienen solo conversaciones baladíes que no van a resultar en nada provechoso. De esta manera el encuentro entre los padres y madres de los novios fracasa.

De forma distinta a la historia que se describe en el cuento, Mario es incitado por sus amigos y los acompaña a una fiesta casual donde conoce al fin a otra chica muy fresca y alegre, con quien sostiene un romance fortuito. En la siguiente secuencia a Delia se le advierte aparentemente celosa pero aun así no abandona su luto que ahora le resulta a su novio un flagrante insulto debido a la relación formal pero tan distante que han ido sosteniendo. Sin embargo ella evade las observaciones críticas de su nuevo galán con expresiones que la colocan tan necesitada de comprensión: "No soy libre, Mario, estoy atada a algo. A mí misma", le declara. Dicha sensación de encierro es producto de una negación a sí misma que se deriva en una recurrente incapacidad de poder darse a los demás, y como una acción de auto-confinamiento a la soledad.

La película realiza saltos de un tiempo a otro que se presentan en el mismo ejercicio de toma secuencia, provocando con este recurso el avance mediante una 
rapidez trepidante, la introspección de tipo sicológico de la protagonista y la incertidumbre por la confluencia en un tiempo tan comprimido del pasado y el presente, del mundo real (de los vivos) y el mundo evocado (de los pretendientes que han muerto).

Ella hace maldades inocentes - y algunas veces hasta crueles- a las mascotas de su hogar: al pájaro de la jaula le quita la galleta que ella se come mientras se retira muy gustosa, al gato le derrama su tazón de leche, al pez lo saca de la pecera...

Sus propios padres comienzan también a preocuparse por la conducta rebelde, pero cuando ella va a ser interpelada, reacciona violenta. "Asquerosos" les dice, para luego revelarles -como un ejercicio más de sus caprichos y autodeterminaciones- que ha decidido en un mes casarse definitivamente con Mario. Van entonces a regresar las imágenes múltiples en los espejos donde se proyectan los distintos momentos climáticos de sus tres diferentes novios, agilizando la secuencia escénica y a la vez reforzando el perfil de la protagonista tan atractiva como cruel. Esta estrategia cinematográfica de monstration como la define André Gaudreault, va a permitir también abundar en los "vacíos" del cuento explicitando mediante la imagen, momentos intensos como las ya mencionadas tomas repetitivas de las muertes de los galanes; dichas reiteraciones no presentan perspectivas múltiples sino que con su repetición idéntica, refuerzan un punto de vista único que viene a demarcar el carácter frío de la protagonista por su inmutabilidad ante la muerte de sus propios prometidos. Esta mostración escénica va a apoyar el desarrollo de una diégesis no mimética, bien aprovechada en la mencionada reiteración de algunos pasajes de la historia pasada y violenta de la joven.

En ese sentido se conecta el reclamo de Antonin Artaud (1896-1948) para quien "la rapidez, pero, sobre todo, la repetición, la insistencia, la vuelta sobre sí mismo" es fundamento del cine que debe abordar los estadios culminantes del alma y las atmósferas que actúan -dice- "sobre la materia gris del cerebro" (Artaud 10). La intención de lograr un efecto sacudidor en los espectadores, según 
este autor, es la razón por la que se pretende colocar en un primer nivel la naturaleza sicológica que se desborde hacia un plano de interiorización de los personajes.

En el caso de Delia, la rapidez con la que da evasivas y que va a derivarse en el comprensible fastidio por parte de su prometido, se complementa con la ya referida velocidad de las imágenes que se hacen presentes mediante los abruptos saltos temporales que sirven a su vez de marco para anunciar el episodio final: ella le ofrece -apegada a la narración del cuento- sus infaustos tentempiés. Sin embargo cuando Mario está a punto de tragar el bocadillo, timbra el teléfono como una salvación más que venturosa. Del otro lado de la línea habla Raquel, la chica con quien éste sostuvo su affaire, evitando con la oportuna llamada el trágico como marcado desenlace fatal. Parece entonces que el mundo exterior, oxigenado, rescata a Mario del ambiente encantado y corrompido que se ha erigido alrededor de Delia. A ella al final, solamente le queda sollozar dándose cuenta quizá de que sus tretas criminales han sido descubiertas.

Igual que le sucede a la Circe mitológica, Delia va a ver truncado su deseo perverso aunque no por la astucia o mañosa habilidad del héroe en peligro como se aprecia en el caso de Ulises, sino por la irrupción de un elemento externo que incidirá en la preservación de la propia vida. Circe ha sido vencida.

Por su parte como hace notar Robert Stam, el proceso de adaptación cinematográfica: "involucra dos textos semióticamente diferentes basados en una misma narración" (Stam 84) que en este caso y debido quizá a la participación del propio cuentista en la elaboración del guion, el resultado fílmico aprovecha las aperturas que propone el cuento para sostener adecuadamente su progreso aristotélico mediante la ampliación de algunos pasajes o con el desarrollo de ciertos personajes. De esta manera la incorporación de los dos amigos de Mario que le van notificando y confrontando de forma tan directa sus puntos de vista, la participación puntual pero elocuente de los angustiados padres de los novios o la llamada libertadora de Raquel hacia el final de la película, inciden de una manera atractiva en la evolución de la trama. 
Este producto audiovisual de Manuel Antín se coloca en un tipo de resolución que mucho abona a la contada estética "de la crueldad" desarrollada por Artaud, pues el género fantástico ampliamente experimentado por Cortázar propicia una subversión de los valores trastocando en cierta manera la lógica y perspectiva que si bien no se aleja completamente de la narrativa convencional, propone una mirada interesada en propiciar un espacio menos cómodo al espectador a quien se le pretende por esta vía con/mover; es decir sacudirlo, catapultarlo a un espacio inhóspito. Escribe Artaud: "Reivindico, pues, los films fantasmagóricos, poéticos, en el sentido denso, filosófico de la palabra, films psíquicos" (Artaud 9) cuyos tratamientos incorporan aquellos temas sicológicos abigarrados o los tratamientos introspectivos minuciosos que exploran en el carácter de los personajes más que en las circunstancias que los rodean.

"La crueldad" en Artaud va a ser concebida como una estrategia detonante que le devuelva al arte su concepción primitiva, apasionada, dislocada y convulsa. Mediante un proceso de condensación, crueldad va a significar decisión implacable llevada a sus máximas consecuencias, determinación absoluta e irreversible. De esta manera, la propuesta del cineasta argentino se vincula a los preceptos anunciados por Antonin Artaud en donde la vida ocurre como un espasmo, vibrante y sensible como son los tortuosos sentimientos de Delia.

\section{Recepción de la película.}

En este apartado se desea señalar que el producto fílmico aquí mencionado no se desentiende de la esencialidad temática del texto y que, más allá de contraponerlo o desviarse de la narración contenida en el cuento, apoya la intención autoral por reflejar un ambiente urbano e ineludiblemente bonaerense en donde la personalidad de la protagonista perfila una maldad irrefrenable. Delia Mañara aparece tanto en el cuento como en la película como el eje de la trama y 
sus malévolas intenciones son producto de cierta inestabilidad emocional inexplicable.

Solo una sutil diferencia va a estar señalada al final de la película, ya que en el cuento Mario se lanza contra la joven cuando descubre los pedazos del bicho asqueroso adentro de su mazapán y pretende asfixiarla con sus propias manos. A esta violencia explícita se suman en el relato la anunciación de un gato que se arrastra con las astillas clavadas en los ojos y la idea de que los padres de ella, los Mañara, agazapados en el comedor, abogan para que Mario quizá pueda estrangular con sus propias manos a la chica a fin de romper la cadena de intenciones malsanas. Si es así, entonces el texto literario va a resultar más elocuente en el sentido que da sitio razonable al asunto fantástico, pero en cuyo caso el filme resuelve el final mediante la inesperada llamada de Rebeca que va a propiciar el regreso de los personajes a la rutina diaria, rompiendo de esta manera el encantamiento.

El final de la película incita a preguntarse ¿cómo supo Rebeca que Mario estaba en la casa de su prometida? ¿En verdad ella se atrevería a llamarle directamente a la casa de la novia? Y sobre todo teniendo en cuenta que no hay una razón aparente ¿por qué habría de telefonearle? Sin embargo estas salvedades bien se libran en el esquema de los aspectos que no acaban por aclararse del todo y que persisten no sólo en la ficción sino también en la vida misma.

Los resultados de esta filmación obedecen a una estética generacional de los años sesenta en Argentina cuyos realizadores son jóvenes con poca experiencia en el ámbito profesional que tratan de suplir con el riesgo volcado hacia ideas renovadoras, resultando propuestas más bien intimistas, con pocos diálogos y de actuaciones concentradas (Ros Cases 1) que encontrarían en Antín, un natural enganche a la literatura abierta y sugerente de Cortázar.

Aun cuando esta cinta se proyectó en el Festival Internacional de Cine de Berlín (1964) y fue vista dentro de la programación del Festival de Cannes de 1965, la recepción en Argentina no resultó del todo grata como lo hace notar la crítica de Antonio A. Salgado en Tiempo de Cine: 
En cuanto al personaje de la muchacha, estaba más logrado en el cuento, donde efectivamente un aura misteriosa lo envolvía. Había en ella algo fascinante -tal vez malsano-, encantador y cruel. En el film, en cambio, el enfoque es más realista. (Salgado 1)

Al parecer el público más que angustiarle la actitud de la protagonista, parecía divertirle, contrariando la intencionalidad de sus creadores. No se entendieron las razones no visibles de Circe para rechazar la relación sexual con sus pretendientes a quienes induce incluso a la muerte. La crítica quiso comprender a la protagonista como una metáfora de Argentina como "un país solitario habituado a autosatisfacerse" (Sández 76). En lo que respecta al desempeño del director, apunta Salgado que este: "Suele confundir la expresión cinematográfica con el rebuscamiento técnico y esto le da al film una apariencia molesta" (Salgado 1).

Por otra parte la nota sin firma que publicó en su momento La Prensa resultó también determinante para la apreciación adversa de la película señalando categórica que "Antín ha tomado un cuento confuso y lo ha complicado hasta el delirio... el producto de todo esto es de calidad muy pobre" (https://es.wikipedia.org/wiki/Circe_(pel\%C3\%ADcula 1). Una especie de frustración va a resentirse en este director apodado cariñosamente como «Maneco», provenida de su ingrata experiencia cinematográfica. Él mismo confiesa:

yo estaba fracasando con una película tras otra, mi padre cuando yo había dejado mi trabajo (escribía historietas en una editorial) para dedicarme al cine, me había dicho con paternal resignación que yo iba a terminar en Pampa y vía. (Antín 2)

No sabemos si la publicación de notas críticas como esta fue una razón determinante por la que Cortázar ya no participó en la adaptación de los otros 
cuentos suyos que vendrían con cercana posterioridad. En 1965 se filmaría Intimidad de los parques de la mano del mismo Manuel Antín en cuya cinta aglutina "El ídolo de las Cíclades" y "Continuidad de los parques" donde el argumento refiere de soslayo aspectos de la cultura minoica que van a presentarse engarzados por un fatídico triángulo amoroso. Una parte de esta película se filmó en Lima y Machu Picchu, razón por la que la magnífica ciudadela arrobará al espectador convirtiéndose involuntariamente en la auténtica protagonista de la película y desplazando la tensión entre los personajes inmersos en las situaciones limítrofes del discurso fantástico que a toda luz se advierte en estos cuentos.

Con nuevas adaptaciones a otros relatos de Julio Cortázar vendrían más adelante mejores apreciaciones por parte de la crítica especializada, aunque dichas versiones ya no fueron a partir de sus textos enmarcados en aspectos de asunto mítico. Estos trabajos se filmaron por experimentados y reconocidos directores como por ejemplo Jean-Luc Godard (cuya película Week-end tuvo como punto de partida el cuento "La autopista del sur") o Michelangelo Antonioni (Blow-up concebida a partir de "Las babas del diablo") que ganó los premios de Mejor Película y Director de la National Society of Film Critics en 1966, quizá porque como señalan Cepelledo y Melendo, esta puesta en pantalla es singular en tanto propone un sugerente complejo narrativo apegado al contexto paradigmático de la "modernidad cinematográfica" que se opone al modelo de Hollywood. El director italiano propone una ambigüedad en la explicitación de la enunciación y la desarticulación del relato clásico privilegiando la imagen sobre la historia, considerando también un proceso de autorreflexión entre la realidad y la ficción que dialogan activamente en el filme (Cepelledo y Melendo 234-235).

\section{Conclusiones.}

Como resultado de este recorrido puede llegar a advertirse que algunas obras literarias de Cortázar también interesadas en los temas de corte mitológico, 
han arribado al cine con una suerte irregular propiciada no ya por los indiscutibles alcances de sus propios textos literarios sino debido a las estrategias y técnicas que han puesto en ejercicio sus realizadores.

En el caso específico de "Circe" llevada a la pantalla con el título homónimo, ni la intervención de nuestro autor como co-guionista pudo asegurar la eficaz recepción por parte de la crítica especializada. En la película desmerece el "desplazamiento del elemento temático fantástico en favor de los procesos psicológicos de los personajes" (Ros Cases 7) que fueron colocados en un orden de mayor interés para resaltar el trabajo artístico de Antín. Es probable que la identificación de este cineasta con un pasaje de su juventud fuera la que propició remarcar el perfil sicológico de la protagonista, que las convenientes estrategias fantásticas del relato adaptado:

leí un cuento, "Circe", que me pareció la historia de mi vida... yo en ese momento tenía una novia muy abusiva, en esa época se llamaban novias de zaguán. Y me hacía sufrir mucho mi novia de zaguán. Sentí que había una enorme relación entre ese personaje monstruoso, esa bruja maldita, y esta novia mía. (Antín en Peña 42)

Derivado del pasaje anterior puede dilucidarse entonces que el ejercicio de Antín se sospecha como parte de cierto exorcismo que se decanta hacia la creatividad. La naturaleza de su filme resalta pues la infidelidad amorosa, la presencia de la mujer y en particular los rasgos inexplicables del carácter de Delia, desplazando los hallazgos inmejorables de Cortázar en razón de su labor dentro de la literatura fantástica.

Posterior al tropiezo que significó la reacción hermética para esta película, otros cuentos de Cortázar corrieron mejor suerte. Los productos ya emblemáticos para la filmografía europea y mundial como son las películas de Antonioni y Godard, supieron poner en práctica mecanismos adecuados de condensación, puntos de vista o recursos técnicos innovadores. La versión de Antonioni al 
cuento de Cortázar, por ejemplo, le otorgó una estatura adecuada a las estrategias del texto literario trasladándolas de manera eficaz y dinámica al lenguaje cinematográfico mediante un diseño narrativo novedoso que en esta ocasión bien supieron apreciar los críticos.

Como señala Robert Stam, los estudios sobre la adaptación dan por asentado que los referentes fuente o de origen son literarios (Stam 109); sin embargo su traslación al cine requiere de la intermediación que convoque otros elementos en tanto se trata de la construcción de un nuevo producto estético. Los hipotextos fuente deben transformarse mediante una compleja serie de operaciones que ciertamente no siempre se ensamblan de manera adecuada propiciando en consecuencia un alejamiento por parte de la audiencia y el menosprecio de la crítica. En este sentido el ejercicio de intertextualidad narrativa que pudiera representar el traslado del cuento a la pantalla, requiere de otras estrategias creativas que propongan nuevas maneras de acercamiento al discurso estético en virtud de poder satisfacer la expectativa de los espectadores.

Explica adecuadamente Mariana Sández que la colaboración creativa entre Antín y Cortázar para la escritura del guion significó un pacto, un intercambio de percepciones y estilos muy enriquecedor para ambos (Sández 122-123). A pesar de la distancia geográfica entre ambos, uno en París y el otro de Buenos Aires, se valieron de la comunicación mediante cartas y también por medio de cintas grabadas. Cortázar puso en ejercicio su amplia experiencia como literato e indudable cinéfilo mientras que Antín proporcionó su ánimo fresco y experimental; sin embargo como se ha anunciado, el resultado en esta ocasión no cristalizó adecuadamente.

De cualquier forma resulta imprescindible considerar el producto audiovisual derivado de aquella relación puesto que permite un acercamiento a esta otra faceta colaborativa del inmejorable narrador, aquí bajo el crisol de la generación cineasta argentina de los años sesenta. Como se ha mencionado, la calidad de los relatos de Cortázar ha encontrado en otros directores de cine más 
afortunados resultados. Sus textos literarios son invaluables materiales para la labor de los adaptadores.

\section{Bibliografía}

Antín, Manuel. Dir. Circe. Guion de Manuel Antín, Julio Cortázar y Héctor Grossi. DVD, blanco y negro, 1964, 59'53".

. "Manuel Antín habla de Julio Cortázar. Su relación y sus películas", 2017, http://www.geocities.ws/juliocortazar_arg/antinrep.htm.

Artaud, Antonin. El cine. Alianza, 2010.

Bernárdez, Aurora, et. al. Cortázar de la A a la Z. Un álbum fotográfico. Alfaguara, 2013.

Cepelledo Moreno, María Paz, y Ana Melendro Cruz. "Narración y sabotaje en Las babas del diablo y Blow up" en UNED Revista Signa 22, 2013, pp. 227 $-243$.

Circe (película). https://es.wikipedia.org/wiki/Circe_(pel\%C3\%ADcula, 2017.

Cortázar, Julio. "Circe" en Cuentos completos 1. Alfaguara, 1994, pp. 144 - 154. . "Los Reyes" en Obras completas II. Teatro. Novelas I. Ed. de Saúl Yurkievich con colaboración de Gladis Anchieri, pról. "Cortázar antes y después” de Steven Boldy, Galaxia Gutenberg, 2004, pp. 49 - 72.

De la Peña, Ernesto. Obra reunida. Ensayos. Tomo I. Consejo Nacional para la Cultura y las Artes, 2007.

Filer, Malva E. Los mundos de Julio Cortázar, Las Americas Publising Company, 1970.

Gaudreault, André. Cine y literatura. Narración y mostración en el relato cinematográfico. Universidad del Arte - Ediciones de Educación y Cultura, 2011.

Homero. Odisea. Gredos, 2015.

Pavis, Patrice. Diccionario del Teatro. Paidós, 1998.

Peña, Fernando Martín. Generaciones 60-90: Cine argentino independiente, T. 1, Ediciones de la Filmoteca - Instituto Valenciano de Cinematografía, 2003.

Prego, Omar. Julio Cortázar (la fascinación de las palabras). Trilce, 1990.

Ros Cases, Laura. "Julio Cortázar y Manuel Antín: una amistad entre literatura y cine (I), http://literaturaycine.lagallaciencia.com/2016/10/recomendacion77-julio-cortazar-y.html, 2017.

. "Julio Cortázar y Manuel Antín. Una amistad entre literatura y cine (II), http://www.lagallaciencia.com/2016/10/literatura-y-cine-julio-cortazary_16.html, 2017.

Salgado, Antonio A. "Inquieta y presuntuosa". Circe 1964. http://www.cinenacional.com/critica/inquieta-y-presuntuosa, 1965. 
CATEDRAL TOMADA: Revista literaria latinoamericana / Journal of Latin American Literary Criticism Hugo Salcedo Larios

Sández, Mariana. El cine de Manuel: un recorrido sobre la obra de Manuel Antín. Capital Intelectual, 2010.

Stam, Robert. Teoría y práctica de la adaptación. Universidad Nacional Autónoma de México, 2014. 